\title{
A neo-institutional economic approach to automated speed enforcement systems
}

\author{
Laurent Carnis
}

Received: 2 December 2008 / Accepted: 7 January 2010 /Published online: 26 February 2010

(C) The Author(s) 2010. This article is published with open access at Springerlink.com

\begin{abstract}
Purpose From the economic literature, the automated speed enforcement schemes can be interpreted as a specific institution, which works to the reduction of the social cost and enables a better use of road infrastructures. It also represents a particular technology for producing traffic safety. Method Analyzing the ASE schemes through an economic approach stresses crucial characteristics to investigate. Our analysis proposes to follow the economic approach guidelines to identify and to analyze an ASE program (resources, goals and appraisal).

Results and Conclusion This framework also enables a systematic analysis of the ASE schemes by emphasizing on the important characteristics. It makes also possible to establish comparisons between different systems and to be able to identify a specific risk regulation regime. An application is done for the French system (Contrôle Automatisé or CA) and the British program (Safety Camera Programme or SCP).
\end{abstract}

Keywords Speed offenses · Speed enforcement .

Automatic speed enforcement · Institutionalism · Economics

\section{Introduction}

Since the late 1980s automated speed detection systems have gradually come to replace the traditional techniques.

L. Carnis $(\bowtie)$

Department of Transport Economics and Sociology (DEST),

French National Institute for Transport and Safety Research,

Site de Marne-la-Vallée,

Le Descartes 22, Rue de la Butte Verte,

93166 Noisy-le-Grand, France

e-mail: laurent.carnis@inrets.fr
Utilization of such systems has become a clear necessity for any government seeking significant reduction of the traffic hazards associated with excessive speed. It has, in addition, radically modified driver behavior, police handling of the speed question and the approach of government road safety bodies.

The development of the new speed detection method and its adoption by numerous governments has highlighted a considerable diversity both in the actual techniques used and in the operational and organizational modalities. There is an enormous literature devoted to the effects on road safety produced by these systems, with almost all data converging on a resultant significant diminution of the number of road accident victims $[18,36]$. By contrast there are very few studies putting the organizational dimensions of different systems into perspective [6, 8, 33, 37]. Does there exist an adequate means of developing and implementing such systems [19]? And can we define operational modalities and their adaptation to specific issues [4]? How can we proceed to get adequate international comparisons?

We propose to develop a framework inspired by the neoinstitutional economic approach. Indeed the automated speed enforcement (ASE) system can be considered as an institution and thus as a process contributing to reduction of the uncertainty of traffic movement $[25,26]$ (Section 2). In economic terms, they represent specific and appropriate combinations of means to reach particular aims. By following the neo-institutional economic approach, it allows for the designing of an analytical framework identifying the means, objectives and results associated with them. It also proposes criteria for the systematic identification of these systems (Section 3). This paper also proposes a rough application to the French ASE (Contrôle Automatisé) and the Speed Camera Programme implemented in Great-Britain to illustrate the potentialities of such an approach (Section 4). 


\section{Automated speed enforcement system: an neo-institutional perspective}

The ASE system can be interpreted as an institution whose purpose is the control of the hazards associated with road use and the reduction of the infrastructure's shared costs in terms of exchange and use, or externalities. ${ }^{1}$ It should also be emphasized that an institution includes formal (speed limit for instance) and informal rules, which constraint human behavior ([26], p. 4). They represent resources or means mobilized for reaching specific aims.

\subsection{Towards a definition of ASE system}

ASE is one of a range of possible ways, among many varied speed detection devices (laser handguns...), of identifying those who fail to observe speed limits [12]. Comparisons become possible because there are also different kinds of ASE organizations. Is there a real interest of establishing comparisons between a national speed program and few radar devices installed through a city? We propose to define the ASE systems by five basic characteristics in order to make true comparisons possible.

(1) ASE systems rest upon automation. The device uses relatively sophisticated computerized techniques enabling a large reduction of the number of human interventions in the process of offender identification and sanctioning (direct digital network transmission of data, computer identification of license plates and of offenders' addresses...).

(2) ASE systems allow massive deterrence. The device means a significant increase in the intensiveness of police surveillance and in the probability of effective detection of offenders.

(3) ASE systems imply more finely honed division of the enforcement process. The tasks of detection and sanctioning are clearly separated. That is not always the case with the traditional systems, where the police officer can behave like a "judge" by being able to modulate tolerance margins and thus establishing the legality or otherwise of certain speeds [36] or by showing leniency $[13,31]$.

(4) ASE systems constitute an integrated system and need a specific organizational rationale. The ASE system rests upon a special institutional design, with the creation of a specific organization to manage and to coordinate the program (adaptation of the judicial framework, definition of specific organizational rules) [11]. In brief, the overall system is an integrated one calling for coordination mechanisms and functional consistency.

${ }^{1}$ Costs borne by agents, whereas the decision was taken by another one.
(5) The implementation of ASE systems are based on a prior political decision implying political effects and have to be supported by political commitment. The ASE system is backed by real political determination. This political decision is generally part of a broader strategic plan either aimed at reduction of road hazards or reflecting a governmental priority (modernization of administration or a search for efficiency). In a way it calls into question the previous modalities of interaction between the different authorities (police forces, department of justice, department of transport...), and between those authorities and road users.

Consequently, the setting up of an ASE system involves choices concerning organizational and institutional dimensions. It is also a costly alternative to reduce traffic hazards. It implies to invest large amounts of resources. How could we understand the choices to implement such a system? The neo-institutional economic approach appears very useful to bring first elements of answer.

2.2 An neo-institutional economic definition of automated enforcement systems

The road network facilitates exchanges of goods, ideas and persons via the mobility it allows. The rapidity with which such transfers take place means a certain reduction of the distance factor and of the transaction and communication costs between individuals. It means also an increase of costs with more traffic hazards [15].

In this context the installation and proliferation of automated speed enforcement systems can be seen as the appearance of a relatively effective institution aimed at reducing the costs associated with widespread vehicle use by offering road users a better grasp and control of their environment ([24], pp. 9-10). Relevant here is the definition put forward by North ([25], p. 97) 'They [institutions] consist of both informal constraints (sanctions, taboos, customs, traditions, and codes of conduct), and formal rules (constitutions, laws, property right).' More specifically, the role of institution consists in producing a stable structure for individual actions and so allowing for reduced uncertainty in every-day decisionmaking, and especially here for the driving choices. They work as guides for human interaction - the user can expect, for example, a certain uniformity of traffic speeds-but also represent constraints, modifying the field of the possible in respect of individual choices: speed-related behaviors violating a defined threshold, for instance, will be sanctioned ([26], p. 3 sqq). In this way the ASE system functions as a road traffic cost-cutter.

More precisely, the ASE system represents an institution which is itself integrated into an institutional structure. Its 
implementation does not take place on virgin soil. ASE means that the government has to decide public spending and to make trade-offs among different interventions. ASE systems is part of a more far-reaching policy of transport safety $[6,30]$. It is a part of a more general speed strategy [1]. Then potential interlinks between different organizations in charge of speed enforcement have to be taken into consideration. It must integrate into and coordinate with the traditional road safety activities of the police force $[9,11]$. The institutional frame means also the interweaving of formal constraints (the Highway Code, the Criminal Code) and informal rules (the specific use of the devices, which can be left to the judgment of police officers, social condemnation of certain speed-related behaviors...), which yield interactions whose outcomes are sometimes unexpected.

ASE constitutes a sophisticated kind of institution, based on technology and organizational design. It aims at managing the human environment and its complexities. The driver is not conceived as an "automata" whose excess speed would reflect only an error of judgment, but individuals with specific preferences, capable of defining strategies for avoiding speed checks and challenging the devices concerned [5, 27], and who can draw on resources that are technical (radar detectors), social ("knowing somebody" or social network) and political (mobilization and protest involving the media and politicians).

\section{ASE systems as productive process}

The application of neo-institutional economic analysis tools to the study of ASE systems enables the method to be seen as a specific technique for production of detection and identification of speed limit offenders. In this way, it remains possible to apply an overall analysis by suggesting that such systems, which are designed and framed differently, imply mobilization and combination of different resources (outlays) with a view to attaining a particular goal which are going to produce outcomes (advantages) that may ultimately be subjected to evaluation.

3.1 The means: the question of production factors and of productive technique

Among the means several separate dimensions can be identified: the operational, technical and organizational. The operational dimension first of all includes a characteristic of mobility of the system (a). Systems may be fixed as in Tasmania, mobile as in Queensland ${ }^{2}$ and Denmark [2]. They may also be mixed as in France [9]. The characteristic of transparency (b) signifies that the authorities can either use

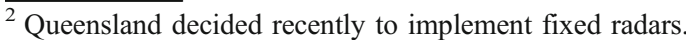

detection that is concealed (as in Victoria) or made public via warnings in the media, on the Internet or via appropriate roadside signing near detection areas (as in Queensland). ASE systems can be associated with a communication policy (c). This may involve advertising campaigns or communication measures using the various media [7]. System density (d) has emerged as a crucial characteristic of any detection system, as it indicates the extent of surveillance and of the efforts being put into detection by the authorities. System density can be evaluated in different ways: according to the number of devices in operation, the hours of operation for instances. Another way of proceeding is to relate the effort made to the number of drivers, the population or the size of the network under surveillance [34]. In addition, fixed devices may be used at random or continuously. Detection areas can be checked regularly, but also discontinuously by using mobile devices. Thus permanence of detection (e) represents another crucial operational dimension when halo phenomena are taken into account. Cross-referencing of temporal and spatial halo effects enables definition of surveillance grids [12].

The technical dimension is directly related to the productive conditions and the techniques of production used. To be taken into account here are the judicial framework (a) and the rights of the offender (the right to challenge the alleged violation, application of the owner onus principle...). The technical dimension also includes a financial characteristic (b). The detection system may be based on a selffinancing policy (cost recovery system in Great-Britain until 2006) or on a direct financing by the authorities. This characteristic also raises the issue of the how the accrued revenue is to be used, which depends among other things on the constraints of public finance laws or on the existence of a no-fault accident system as it is operated in Victoria (Australia) or in New Zealand for instance. The lessons drawn from the economic analysis of illegal acts, which shows that the level of deterrence hinges on a combination of effects associated with the intensiveness of surveillance and the severity of the sanction stresses the importance to define an optimal deterrent policy (c) [3, 13]. Thus the ASE systems can be characterized by different combinations of surveillance and sanction. It is also crucial that the scale of penalties and the modalities of the sanctions are taken into account, as they affect the functioning of the whole system (fines and/or demerit point system $^{3} \ldots$..). The technical dimension also includes the installation criteria (d) for the detection devices (abnormal driving speed level, black spot...). Lastly, this dimension involves the technological choice (e)

\footnotetext{
${ }^{3}$ In France, the implementation of an ASE system drove to an huge increase of people having lost their driving license with repeated speed offences. Henceforth some road users drive without driving licenses to keep their jobs. ASE system can then represent a cost to mobility.
} 
made by the authorities for or against the use of digital photographic processes with more or less sophisticated levels of automation and which are more or less costly.

The organizational dimension framed the location of the decision-making center (a) which is characterized by a process of more or less centralization within the framework. The organizational structure also necessitates specifying the organization in charge of the operational dimension, any connections it may have with other stakeholders, and its institutional integration (b). This may be an administrative or action program body which decides on the strategy to be adopted, while the strictly operational running is in the hands of the police. The system can be entrusted to an administrative body or even to a private company as part of a delegation contract or be managed directly by the police organization. Thus arises the issue of the status of the operator and how it is paid for (c): administrative agency, police body or private company. Lastly the operational dimension poses the question of the consequences of the institutional change (d) entailed by the implementation of an automated system capable of supplanting traditional procedures. In Great-Britain, the implementation of the Speed Camera Programme was followed by a decrease of $20 \%$ of police officers dedicated to traffic safety tasks ([28], p. 11).

3.2 The aims: defining the objectives of productive organization

The objectives sought by the introduction of an automated system are just as numerous. However, the common goal consists in reducing the costs of use of the road traffic infrastructure. The aim is to reduce transaction costs by diminishing the uncertainty involved in vehicle use as we showed in Section 1. These objectives may be (a) a reduction of road hazards at both local and national level. Obviously whether the goal is an overall or local effect will influence the terms and conditions of the system. ${ }^{4}$ The quest for a reduction of road hazards can also proceed from a determination to reduce (b) traffic speeds. More precisely, it can involve reducing the average speed, the most excessive speeds, or reducing the number of drivers who commit offences. This public policy can be a response to (c) environmental considerations, so as to facilitate management of congestion situations, pollution or such specific risks as driving in tunnels. There can also be a fit with (d) wider political aims such as the sustainability of the transport sector and, via traffic diversion, the redistribution of movement to other modes of transport.

\footnotetext{
${ }^{4}$ In general mobile devices allow for overall deterrence, while the fixed equivalents enable solutions for local problems whose effects on the rest of the network remain limited.
}

3.3 The results: the outcome of production efforts

The mobilization of resources and the choice of a production technique enable the effective implementation of an ASE system whose functioning produces particular results. These results can be interpreted in terms of (a) the evolution of speed indicators: average speed, speed distribution, speed broken down according to the type of networks or the type of users. The impact on (b) the volume of speed offences is also crucial. What has to be taken into account here is their breakdown according to the networks, the types of vehicles and the level of excess speed. Further indicators could be second/repeated offences and second/repeated offenders. The effects on (c) road hazard reduction can be assessed via changes in the number of victims and accidents and death rate per head, per driver or per kilometer traveled. Calculation of road hazard reduction cannot be restricted to the fall in the number of road accident victims on a given network, but must also include other speed-related damage (medical and rehabilitation expenses for road accident victims and the cost of material damage).

For the authorities a broader, more ambitious approach involves a correlation between the gains and the outlay associated with the introduction of automated speed enforcement. This means adopting (d) benefit-cost approaches and correlating the implementation and running expenses with the savings on damage, which needs that regular audits are made. This policy is above all concerned with efficient, effective use of resources. The benefit-cost approach is not exclusive, some other alternatives are possible as costeffectiveness, or regulatory budget approach [22]. Another result consists in focusing on (e) the system's financial dimension to take into account its potential sustainability, improvement and eventual expansion. Lastly (f) the social acceptability and public perception of the system represent a further measurable result of the action taken by the authorities [17]. This result allows for evaluation of the reception given to the goals, the functioning and the results of the detection system to identify any changes in this regard and, when necessary, to enable the authorities to grade their communication policy, and to modify the circumstances of installation of the devices and the severity of the sanctions. This serves also to demonstrate that the aim of the exercise is to reduce traffic hazards and not, as opponents of this type of detection frequently allege, to fill the coffers of the state by fiscal means.

\section{A special application of the model to the French CA and to the British speed camera programme}

In this section, our neo-institutional economic framework is applied to two ASE systems: the French CA (Contrôle 
Automatisé) and the British Speed Camera Programme (SCP). We first present briefly the two systems by describing how they are organized, the used means, the defined objectives and their results. Then first elements of synthesis are proposed and implications coming from the previously defined framework are identified (Table 1).

\subsection{Study design}

We used the case studies approach for our research purpose [35]. This investigation rests upon the access to official documents and administrative reports. The governmental websites, academic studies and the analysis of official statistical data series also provided very useful information. We were invited by police organizations to attend speed enforcement operations. Interviews with researchers, police officers and officials in charge of the operation of the ASE system in France and in Great-Britain were realized. Our research also benefited from presentations concerning the working of both Traffic Camera Offices and from scientific exchanges with scholars.

France and Great-Britain are two European countries, which implemented an important ASE system to reduce the number of road accident victims and damages and to enforce speed limit. Although Great-Britain introduced the speed cameras for the first time in 1992, the study only focuses on the period 1999-2006 concerned with the National Safety Camera Programme. The French system starts with the installation of first devices in November 2003. Since its implementation, it has been knowing an ongoing development process: the government recently announced that 4,500 speed and red light cameras will be installed by 2012 .

\subsection{Historical background and brief presentation of both systems}

\subsubsection{The British case}

The British government experimented the first speed cameras in London in 1992 with the West London camera demonstration project [23]. In 1995, a first cost-benefit analysis showed clearly that the program generated 'substantial net benefits' [21], which was confirmed by other further studies ([16], pp. 5). However the report mentions a mismatch for the funding responsibilities and defends implicitly the "netting-off" system for funding the program. In 2000, after a short experimentation period, the national recovery scheme was introduced and local safety

\footnotetext{
${ }^{5}$ This funding scheme was also called 'hypothecation'. It means the safety camera programme is self-funded, the revenues of fines collected covering the costs for operating the cameras managed by each local partnership.
}

camera partnerships operate the system throughout the police jurisdictions. A new scheme has recently been launched by the government in April 2007, which implies a direct funding under the supervision of the Department for Transport.

The local authorities decided to install more automatic devices, because of good results obtained [8]. Indeed, numerous researches showed that the SCP constitutes an effective system to reduce speeding behaviors $(-31 \%$ of speed offenders between 2001 and 2004) and the number of road hazards (the number of people killed or seriously injured were reduced by $42 \%$ at camera sites) [10]. It is a cost effective system, because it yields 2.7 more pounds for each pound it costs. The number of speed operated cameras during the National Safety Camera Programme was roughly 5,000 . At present, the government seeks to consolidate the system instead of pursuing its extension.

Different stakeholders join in the working of local partnerships (local government, police organization, ambulance and fire services...). The local partnership operate randomly fixed and mobile radars devices. The British system depends basically on fixed radar devices installed in urban contexts (roughly $45 \%$ of the total number of devices) [11]. The authorities decided to advertise the driver for the presence of a speed control: road signs were installed near the radar devices.

One main institutional characteristic of the British system is the adoption of a self-funding scheme. The local partnership bore the maintenance, operation and installment costs of these devices and is reimbursed with the collected fines. This cost-recovery scheme permits a rapid development of radars devices through the country while insuring the financial sustainability of the different local partnerships. A net revenue of 22 million pounds was yielded for 2003/2004 exercise.

This ASE system rests upon relationships of accountability between the national board and the local partnerships. The national board appeared as a necessity for making possible homogeneous practices of enforcement at the local level, whereas the local partnerships keep on benefiting from operational autonomy, stressing the importance of taking into account local constraints. This autonomy implies different local systems of governance. Polycentrism characterizes this institutional organization.

The British program also gives importance to communication towards the public and to evaluation practices, that allows to benefit from a high public acceptance level of a very intensive program of enforcement. The communication policy is a part of the strategy, not only to improve the efficiency of the programme but also to make the implementation of additional radars devices socially acceptable. Although the SCP was strongly supported by the great part of population, this support decreased with the implementation of additional speed cameras. Moreover 


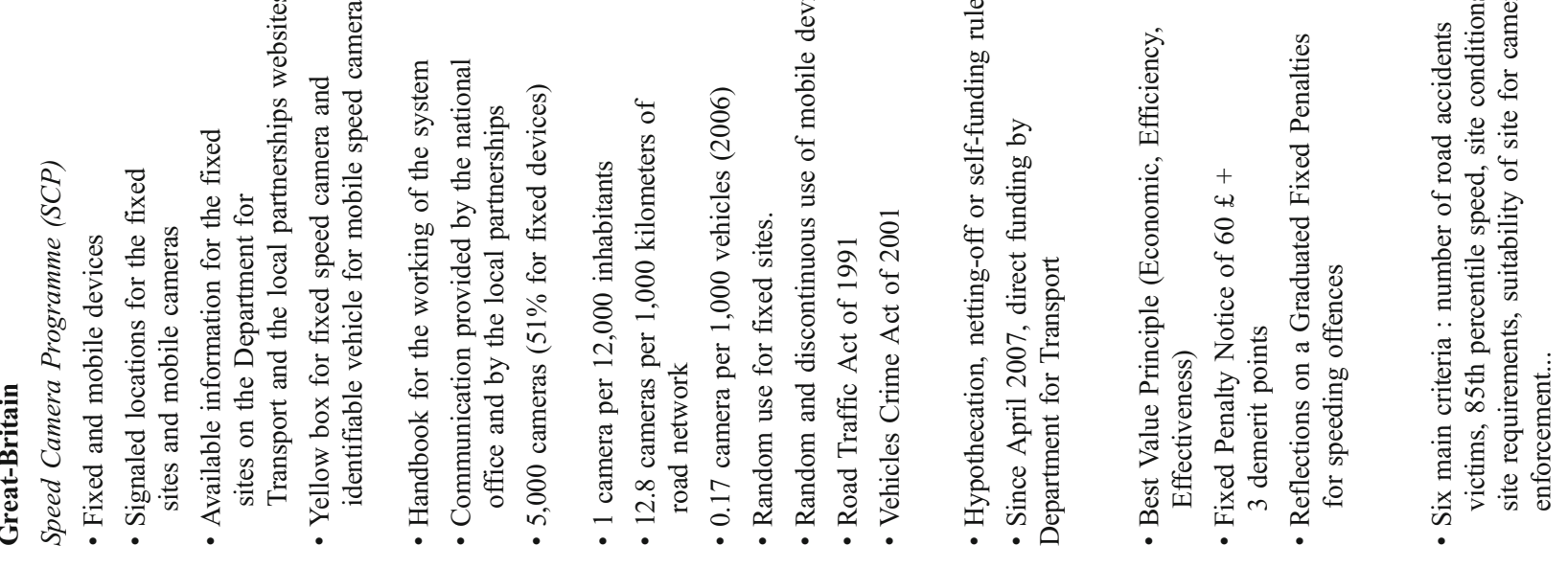

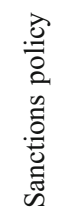

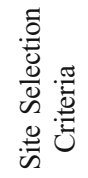



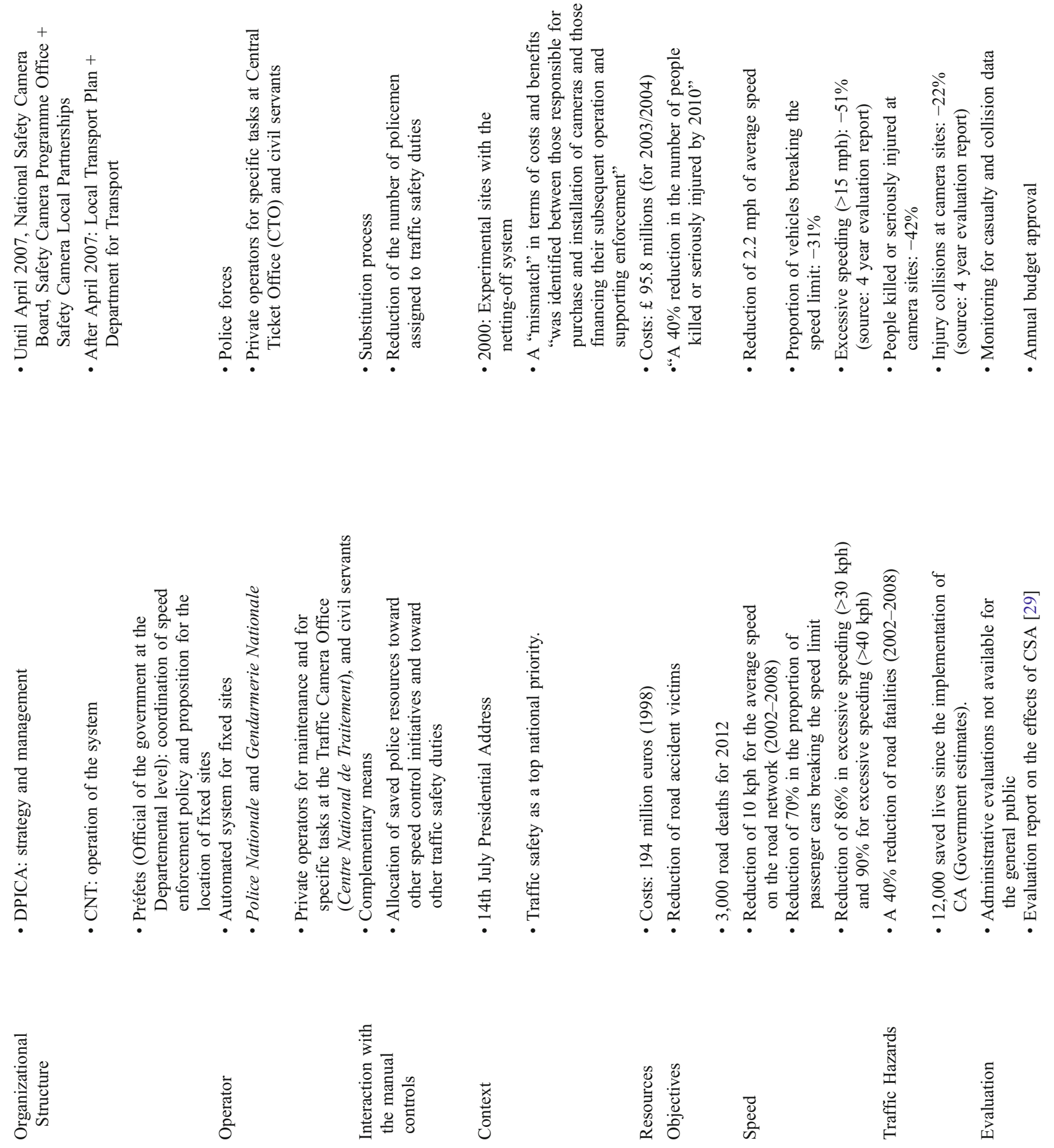

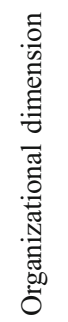

I

产 


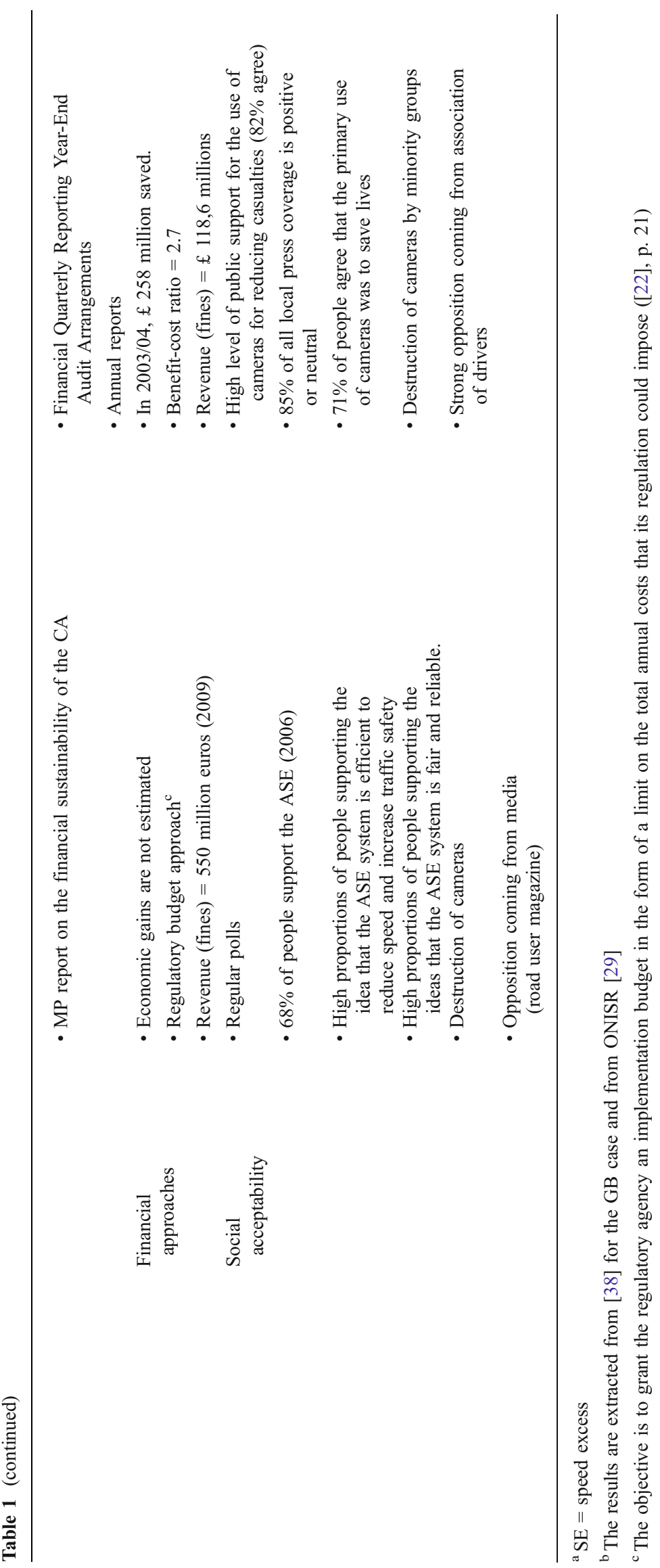


associations of drivers challenge the official results regarding traffic safety figures and dispute the efficiency of automated speed enforcement. The evaluation of this public policy is complex enough to encourage such debate.

\subsubsection{The French case ${ }^{6}$}

After a short experimental period in 2003, the first radar devices were introduced by the end of this year. The deployment of an automatic speed enforcement program was facilitated by a favorable political context with a strong commitment from President Chirac, who declared traffic safety a national top priority. The objective to reduce the number of road accident victims appears more as a political goal than a search for the reduction of the social cost arising from road accidents. There were roughly 7,000 road fatalities before the implementation of the ASE system, and less than 5,000 in 2008. At present, the French system operates roughly 2400 radar devices. ${ }^{7}$ The number of automated radar devices in use comprised $36 \%$ mobile and $64 \%$ fixed. Since the creation of the CA the authorities have been trying to adhere to a proportion of $1 / 3$ unsignalled mobile devices, in the interests of specific deterrence, and $2 / 3$ signalled fixed devices in the interests of overall deterrence. The intention is to combine a crackdown of enforcement with driver education, to mix general deterrence and specific deterrence. The radar devices are installed mainly through the interurban road network. Another strategy followed by the authorities is to grid the road network with speed cameras to deter the road users to commit speed offences wherever they drive, but also to change durably their driving behaviour.

The organization is hugely centralized with the DPICA, ${ }^{8}$ an administrative body in charge of strategic decision and management. The decisions on the choices of location sites are made in collaboration with the representatives of the State at each département. The problems of speed behaviors, the relatively important level of road victims or/and the impossibility to conduct traditional enforcement constitute criteria for choosing control sites. Operational management of mobile devices is handled by the Gendarmerie and the National Police, ${ }^{9}$ whereas fixed devices are fully automated. They are operated without humane assistance.

The main characteristics of the French system are its high technological sophistication with a near complete

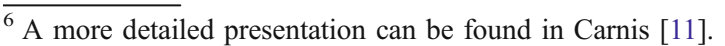

${ }^{7}$ The objective of authorities is to install 500 additional devices each year until 2012.

${ }^{8}$ Direction de Projet Interministérielle Contrôle Automatisé.

${ }^{9}$ France has two national Police forces: the National Police, which is the main civil law enforcement agency, with primary jurisdiction in cities and large towns; and the military Gendarmerie, with primary jurisdiction in smaller towns and rural areas.
}

automation process [29] and a centralized system relatively free of all accountability dimension. The French ASE yielded huge revenues since its implementation. In 2008 the collected fines amount to 550 million euros, whereas the operation costs were 200 million euros. Although the government asserts than 12,000 lives were saved by the ASE system, scientific evaluation and economic analysis were not really undertaken. The French authorities adopted a regulatory budget approach. A dedicated budget is granted to operate the system and to insure its expansion. The system rests upon a direct funding by government. A recent released report emphasized on the financial sustainability of the system. Costs would increase with the expansion of the CA, whereas the revenues would decline with the reduction of committed speed offences. We can expect organizational changes for $\mathrm{CA}$ in a near future.

\subsection{First elements of synthesis and implications}

The British program has many strong advantages. The selffunding rule shows that the public authorities gives importance to a good use of public money. Thus the British system applies the "Best Value" policy, combining the principles of economy, effectiveness and efficiency [14]. The decision to create a guide for operating the program indicates also concern for its social acceptability and the willingness of reaching an homogeneous working among the local partnerships facing different local considerations and constraints. The British program also shows a true ability for resilience with three working and organizing schemes since 1992. Flexibility is one of its main qualities to face a changing environment. The criteria for choosing a speed control site are accurate enough for implementing rationally the radar devices. However, the concern of a good use of public resources transforms this approach into a financial approach through undertaken audits and many financial controls and rules to obey. This could put in danger ultimately the existence of the system itself. Indeed an efficient partnership means a reduction of revenues (because speed offenders are deterred) and insufficient resources to fund its operation in the future. It is undoubtedly one reason explaining the recent adoption of the operating rules of the program. Another major defect is the willingness of political authorities to replace manual police controls by adopting an ASE system to enforce the speed limits. The number of traffic police officers was reduced roughly by $20 \%$ between 1996 and 2004 in GreatBritain. Then it creates a specific division of enforcement labor between the manual speed enforcement and the automatic one, which needs to find appropriate means of coordination between the different organizations. Indeed the automatic devices can not constitute an answer for all situations of speeding behaviors and overlapping situations 
of enforcement have to be avoided to limit inefficiencies. Moreover the punishment scale is not graduated enough. Indeed punishment is weakly commensurate with the importance of the speed excess. ${ }^{10}$ A reflection has to be undertaken on this issue to make more acceptable the system by the public and to introduce fairness among speed offenders. Another point deserves attention. It deals with the optimal size of jurisdictions of local partnerships. Indeed scale economies (reduction of average cost of a unit of enforcement) could be found by reorganizing the frontiers of partnerships to make a better coordination among actors and to reduce the total costs of operation. But it means the audit process does not circumscribe the evaluation of the program to an efficiency in terms of road hazard reduction and a cost-benefit ratio.

The French system also presents several interesting advantages. This system can be termed 'techno-centric', being founded on a centralizing and hierarchic rationale in which the center controls what is done locally through technocratic and technological power networks. Such structure allows to reduce the costs of transaction among the different actors. Coordination is then less costly because decision is taken by a small number of actors. It enables to coordinate the different operators more easily and to reach a relatively homogeneous policy. However the technology used by this system is more expensive than alternative technological devices and implies technical problems of connection with the CTN (Centre National de Traitement or Traffic Camera Office). Another key characteristic is the political dimension of the choice of developing an ASE system to reinforce the traditional techniques of speed enforcement. The existence of a complementary effect has to be stressed: the implementation of such a system does not lead automatically to the disappearance of manual process and to the exclusion of police officers from this operational activity. On the contrary, ASE system enables to allocate released police resources toward the most urgent traffic policing tasks.

However the French system has to face key issues either. The absence of an economic approach to the system implies the impossibility to determine the optimal size of the system, to locate the most urgent sites to give priority for installing the radar devices, and to analyze its financial sustainability. The punishment scale is a little bit more graduated than its British counterpart. However a main critic recently raised against the system is the coupling effect implied by the demerit points on the driving license.

\footnotetext{
${ }^{10}$ It is one consequence related to the working of the fixed penalty. A same penalty is given for different speed excess. Consequently, it is worth for the drivers committing a higher speed excess while bearing a same punishment.
}

Many drivers have their driving licenses withdraw ${ }^{11}$ and drive without it. The coupling effect of a fine and an administrative sanction yields a severe punishment, which was not perceived with the manual speed enforcement because it was associated with a low level of detection. Investigations are also necessary to know more on repeat speed offenders in order to find an appropriate answer and introduce adapted punishment. Finally the homogeneous practices of enforcement can be put into question with the autonomy given to police officers for choosing the location of control for the mobile radars, which stresses the absence of an handbook and the necessity to define more formal rules for operating the system in a similar way.

The French CA and the British SCP illustrates the different possibilities of designing and framing an ASE system. Different institutional frameworks are possible: the level of centralization, the place given to the police organization for operating the speed cameras, the design of governance system, or the importance given to evaluation and economic dimensions. Consequently coordination becomes a crucial dimension for implementing and operating correctly an ASE. It also implies a government has to find appropriate means for producing coordination to make its public policy effective whatever the ASE system implemented.

\section{Conclusion}

The definition of ASE systems identification criteria based largely on a neo-institutional economic approach is a point of departure allowing not only for a balanced perspective on the different automated detection systems, but also for a more extended comparison between different countries. Moreover, economic analysis and application of the economist's tools make possible certain appreciable conclusions for the public-sector decision maker and for this particular public health issue, as we tried to show with an application to two European ASE programs. When the French system is termed 'techno-centric' and the British speed camera programme is characterized by its polycentrism, we emphasize on the importance of the institutional dimension. These particular institutional frames were selected, because the government expected they were the most adapted ones to reach the objectives of public policy. Their implementation would be made more easily considering the country institutional organization. The British system shows a greater flexibility to be adjusted to local considerations, whereas it requires more costs of coordina-

\footnotetext{
${ }^{11}$ In 2008 roughly 98,000 driving licences were cancelled after the driver lost his 12 demerit points.
} 
tion for its operation. The French system with a higher degree of centralization than its British counterpart is less flexible, but it requires a more simple organization for current speed enforcement operation. Contingent considerations are undoubtedly at stake when an adapted institutional design is chosen.

The design of an ASE system as an institution makes uncertainty management a core aspect of the resource allocation process. To conceive ASE system as a particular institution opens new perspectives to find new solutions to fight against traffic hazards. It emphasizes that the traditional vehicle-driver-infrastructure framework used to decrypt the road risk analysis and policy has to be amended by a new element: the institutional dimension. The institutional dimension interacts undoubtedly with the other elements of the traditional triptych, but more investigations have to be made to know the different road risk 'regulation regimes' and to determine the crucial characteristics [20].

Open Access This article is distributed under the terms of the Creative Commons Attribution Noncommercial License which permits any noncommercial use, distribution, and reproduction in any medium, provided the original author(s) and source are credited.

\section{References}

1. ACC and LTSA (Accident Compensation Corporation) (2000) Down With speed: a review of literature, and the impact of speed on New Zealanders, Accident Compensation Corporation and Land Transport Safety Authority, Wellington, New Zealand

2. Agustsson L, Juels GN (2002) Reducing car speed nation-wide: the effectiveness of mobile speed cameras in Denmark in Proceedings of the European Transport Conference. www.etcproceedings.org/ paper/download $/ 552$

3. Becker GS (1968) Crime and punishment: an economic approach. J Polit Econ 78:169-217

4. Blackburn R, Gilbert D (1995) Photographic enforcement of traffic enforcement, synthesis of highway practice 219, National Cooperative Highway Research Program, Transportation Research Board, National Academy Press, Washington, D.C.

5. Bjørnskau T, Elvik R (1992) Can road traffic law enforcement permanently reduce the number of accidents. Accident Anal Prev 24(5):507-520

6. Cameron M, Delaney A, Diamantopoulou K, Lough B (2003) Scientific basis for the strategic directions of the safety camera program in Victoria, Report $n^{\circ} 202$, Monash University Accident Research Center, Clayton, Victoria, Australia

7. Cameron M, Newstead S, Gantzer S (1995) Effects of enforcement and supporting publicity programs in Victoria, Australia, VTI Konferences 4A, part A, enforcement in urban areas, Proceedings of the Conference Road Safety in Europe and Strategic Highway Research Program (SHRP), Swedish Road and Transport Research Institute, Linköping, Sweden. pp 243-253

8. Delaney A, Ward H, Cameron M (2005) The History and development of speed camera use, report $n^{\circ} 242$, Monash University Accident Research Center, Clayton, Victoria, Australia

9. Carnis L (2007a) The French automated speed enforcement programme: first results and analysis, Proceedings of the
Australasian Road Safety Conference Research Policing Education Conference, 2007, Peer-Reviewed Paper, Melbourne, http://www.roadsafetyconference2007.com.au/finalpapers.php

10. Carnis L (2007) L'automatisation des contrôles de vitesse en GrandeBretagne: entre révolution technique et continuité administrative. Rev Int Sci Adm 73(4):661-675

11. Carnis L (2005) Le contrôle automatisé de la vitesse en France et en Grande-Bretagne: Deux régimes de régulation des vitesses distincts in Les régimes français et britanniques de régulation du risque routier: la vitesse d'abord, Groupe opérationnel du PREDIT: GO3, décembre 2005, pp 189-218, France

12. Carnis L (2001) L'apport de l'analyse économique au contrôle des excès de vitesse. Revue Politiques et Management Public, Juin 19 (2):83-103

13. Carnis L (2001b) Entre intervention publique et initiative privée : une analyse économiques en sécurité routière, Une application aux législations sur la vitesse, Thèse de doctorat de sciences économiques, Université de Reims Champagne-Ardenne, Faculté des sciences économiques et de gestion de Reims, 2 volumes, France

14. Department for Transport (2006) Handbook of rules and guidance for the national safety camera programme for England and Wales for 2006/07, www.dft.gov.uk/pgr/roadsafety/speedmanagement/

15. Elvik R (2005) Speed and road safety, synthesis of evidence from evaluation studies. Transportation Research Record 1908:59-69

16. Gains A, Nordstrom M, Heydeyker B, Shrewsbury J, Mountain L, Maher M (2005) The National Safety Camera Programme, threeyear evaluation report, PA consulting Group, University of Liverpool and Napier University, June, 160 pages, London, UK

17. Gains A, Heydeyker B, Shrewsbury J, Robertson S (2004) The National Safety Camera Programme, Three-year Evaluation Report, June, PA Consulting Group, UCL, University of Liverpool and Napier University, London, UK

18. Glauz WD (1998) Review of automated technologies for speed management and enforcement, in managing speed, review of current practice for setting and enforcing speed limits, Transportation Research Board, National Research Council, pp 359-390, Washington, D.C.

19. Groupe de Recherche en Sécurité Routière (1998) Le cinémomètre en sécurité routière, Synthèse des pratiques et des études recensées à travers le monde en regard de son implantation éventuelle au Québec, Département d'information et de communication, Université Laval, Québec, Canada

20. Hood C, Rothstein H, Baldwin R (2001) The government of risk, understanding risk regulation regimes. Oxford University Press, New York

21. Hooke A, Knox J, Portas D (1996) Cost benefit analysis of traffic might and speed cameras, police research series, paper 20 , London, UK

22. Lave LB (1981) The strategy of social regulation, decision frameworks for policy. Studies in The Regulation of Economic Activity, The Brookings Institution, Washington D.C.

23. London Accident Analysis Unit (LAAU) (1997) West London speed camera demonstration project: analysis of accident and casualty data 36 months 'after' implementation and comparison with the 36 months 'before' data, London Accident Analysis Unit, www.dft.gov.uk

24. North DC (1999) Understanding the process of economic change, occasional paper 106, Institute of Economic Affairs, London

25. North DC (1991) Institutions. J Econ Perspect 5(1):97-112

26. North DC (1990) Institutions, institutional change and economic performance. Cambridge University Press, New York

27. Oei H-L (1998) The effect of enforcement on speed behaviour: a literature study, Public Master-SWOV Institute for Road Safety Research, June, 55 pages, Leidschendam

28. PACTS (Parliamentary Advisory Council for Transport Safety) (2005) Policing road risk: enforcement, technologies, and road safety, Occasional Research Reports, London 
29. ONISR (2006) Impact du contrôle sanction automatisé sur la sécurité routière (2003-2005) evaluation, Les Rapports, Observatoire National Interministériel de Sécurité Routière, Paris

30. Paquette G, Beaulieu N (1996) Efficacité et pertinence des radars photographiques dans le contrôle de la vitesse in La Santé urbaine par les transports, Université Laval, pp 212-228, ATQR, Québec

31. Pérez-Diaz C (1994) L'indulgence, pratique discrétionnaire et arrangement administratif. Déviance Soc 18(4):397-430

32. Winder A (2001) Automatic traffic enforcement systems: international approaches, Proceedings of the AET European Transport Conference, held 10-12 September, 2001. Homerton College, Cambridge, 18

33. Wright PG, Gyde NH (1998) Speed camera best practicedevelopments, proceedings of road safety, policing and education conference, Wellington, New Zealand, (2):165-168, Land Transport Safety Authority, New Zealand Police, Wellington

34. Yin RK (2009) Case study research, design and methods, 4th edn. Applied Social Research Methods Series, vol 5. Sage, Los Angeles, California

35. Zauberman R (1998) La répression des infractions routières: le gendarme comme juge. Sociol Trav 1:43-64

36. Zaal D (1994) Traffic Law Enforcement: A Review of the Literature, April, Report $n^{\circ} 53$, Monash University Accident Research Centre, Clayton, Victoria, Australia

37. Austroads (2001) Speed Enforcement in Australasia, 2 volumes, Sydney, Australia

38. Gains A, Nordstrom M, Heydecker B, Shrewsbury J (2005) The National Safety Camera Programme, Four-year Evaluation Report, December, PA Consulting Group, UCL, University of Liverpool and Napier University, London 